\title{
PRE-SOWING SEED TREATMENT WITH PHYSICAL STRESSORS INDUCES CHANGES IN AMOUNT OF SECONDARY METABOLITES IN NEEDLES OF PICEA ABIES SEEDLINGS
}

\begin{abstract}
Mantas KAČIUŠIS, Kaunas University of Technology, Donelaičio str. 73, LT-44249, Kaunas, Lithuania / Lithuanian Research Centre for Agriculture and Forestry, Institute of Forestry, Liepų str. 1, LT-53101, Girionys, Kauno distr., Lithuania mantas14kaunas@gmail.com (corresponding author)

Vaida SIRGEDAITE்-Š́̇̌̌̌IENĖ, Lithuanian Research Centre for Agriculture and Forestry, Institute of Forestry, Liepu str. 1, LT53101, Girionys, Kauno distr., Lithuania, vaida.seziene@mi.lt

Povilas ŽEMAITIS, Lithuanian Research Centre for Agriculture and Forestry, Institute of Forestry, Liepų str. 1, LT-53101, Girionys, Kauno distr., Lithuania, povilas.zemaitis@mi.lt

Vida MILDAŽIENĖ, Vytautas Magnus University. K. Donelaičio g. 58, LT-44248 Kaunas, Lithuania, vida.mildaziene@ vdu.lt Giedrè PAUŽAITĖ, Vytautas Magnus University. K. Donelaičio g. 58, LT-44248 Kaunas, Lithuania, giedre.pauzaite@vdu.lt Kazunori KOGA, Kyushu University, 744 Motooka Nishi-ku, Fukuoka 819-0395 Japan, koga@ed.kyushu-u.ac.jp Masaharu SHIRATANI, Kyushu University, 744 Motooka Nishi-ku, Fukuoka 819-0395 Japan, siratani@ed.kyushy-u.ac.jp Vitalij NOVICKIJ, Kyushu University, 744 Motooka Nishi-ku, Fukuoka 819-0395 Japan, vitalij.novickij@ vgtu.lt

Virgilijus BALIUCKAS, Lithuanian Research Centre for Agriculture and Forestry, Institute of Forestry, Liepų str. 1, LT-53101, Girionys, Kauno distr., Lithuania, virgilijus.baliuckas@mi.lt

Tree resistance to pathogens is related to the general viability of trees, their growth energy, and ability to synthesize and to mobilize secondary metabolites (SMs), usually phenolic compounds, in tissues. The total phenolic content (TPC) in Norway spruce needles was determined during two vegetation seasons in order to compare the chemical background and ability of different Norway spruce halfsib families to synthesize TPC in response to seed treatment with physical stressors: cold plasma for 1 and 2 min (CP1, CP2) and electromagnetic field for 2 min (EMF2). TPC in seedling needles significantly differed between affected and control groups, but differences were stronger exerted during the first year of vegetation. In the first vegetation season, the strongest positive effects on TPC synthesis were induced by EMF2 treatment in 463 and 577 half-sib families, by CP1 treatment - in 457 half-sib family and by CP2 treatment - in 541 halfsib family; in the second vegetation season strongest effects were detected in CP1 treated 457 half-sib family and in CP2 treated 548 and 477 half-sib families. The half-sib families of Picea abies with higher TPC induced by seed treatment with different physical stressors could be more resistant to pathogens and diseases. The variance component of family for TPC variated from $14 \pm 10 \%$ till $17 \pm 11 \%$, and was significant. The interaction of genotype and environment on TPC was as high as $49 \pm 20 \%$.
\end{abstract}

Keywords: Picea abies, secondary metabolites, physical stressors, resistance.

\section{INTRODUCTION}

The National Forest Sector Development Program emphasizes the objective of restoring forest on a geneticecological basis - high quality forest reproductive material. An integral part of this is the selection of forests to increase resistance to various pathogens. Particular attention should be paid to increasing the resistance of the main boreal tree species - Scots pine and Norway spruce. In order to achieve the objectives of the National Forestry Sector Development Program it is necessary to distinguish the most ductile and high-resistance families that are most resistant to various pathogens. Tree resistance to pathogens is related to the general viability of trees, their growth energy, and their ability to synthesize and mobilize secondary metabolites (SMs), usually phenolic compounds, in tissues (Marčiulynas et al, 2019). Studies show that the ability of different genotypes to synthesize AM and mobilize them to against pathogens is variable, therefore the genetic selection is appropriate (Marčiulynas et al, 2019; Thor and Stenlid, 2007; Oliva et al, 2011).

In recent years, much attention has been paid to the positive effects of the treatment of plant objects using lowtemperature or cold plasma and electromagnetic methods, which are being developed by the new scientific field - plasma and magnetic biology. Published reviews (Ohta, 2016; Šera \& Šery, 2018; Bourke, 2018; Filatova et al., 2014; Jiang et al., 2014; Panngom et al., 2014) summarize the findings of many laboratories around the world that seed treatment with low temperature plasma (cold plasma, CP) and electromagnetic field (EMF) significantly promotes germination, plant biochemical processes, biomass gain, and increases yield. Findings are published that CP and EMF treatments are affective tools for seed microbiological decontamination and increase plant resistance to the pathogens (Jiang et al., 2014;

Copyright (C) 2019 The Authors. Published by Vytautas Magnus University. This is an open-access article distributed under the terms of the Creative Commons Attribution License (CC BY 4.0), which permits unrestricted use, distribution, and reproduction in any medium, provided the original author and source are credited. 
Filatova et al., 2014; Zahoranova et al., 2018). Substantial increase in production of SMs and phenolic compounds in seedlings growing from CP and EMF treated seeds was recently reported (Mildaziene et al., 2018). Germination of Norway spruce was efficiently stimulated by seed treatment with EMF, and growth of seedlings - by seed treatment with CP (Pauzaite et al., 2018), in addition it was noted, that Norway spruce seedlings grown from CP-treated seeds have significantly more trichomes (growths that accumulate SMs stock (unpublished observations) indicating to stimulated production of SMs. On the other hand, significant correlations were determined between synthesis of SMs in Norway spruce needles and resistance of plants to pathogens (Ganthaler et al. 2017). The LAMMC Institute of Forestry has an experimental collection established in 2018 of seedling of different genotypes of Norway spruce grown up from seeds treated with CP and EMF. We hypothesized that CP and EMF induce different changes of SM in Norway spruce half-sib families seedlings needles. The selection of more resistant spruce genotypes, including genotypes with additional resistance to physical stressors, can be recommended to forestry companies for effective reduction of pathogen losses. Similar systematic studies of pathogen resistance in tree planting material through physical effects have not been conducted so far.

\section{Research methods}

Seeds of seven different genotype of Norway spruce (Picea abies (L.) Karst.) were collected from the second generation spruce seed orchard in Trakai regional division.

\section{Seed treatment by $C P$ and $E M F$}

Seeds of each Norway spruce (Picea abies (L.) Karst.) genotype were exposed to two different physical stressors: 1) cold plasma or low-temperature atmospheric DBD plasma (duration of exposure 1 or 2 minutes), 2) electromagnetic field (duration of exposure 2 minutes).

Seeds were treated with CP using a controlled DBD (dielectric barrier discharge) discharge device produced in Kyushu university, Japan (Sarinont, Amano et al., 2016) with a homogeneous treatment area of $4 \mathrm{x} 4.38 \mathrm{~cm}^{2}$. The electrical discharge was generated between wire electrodes separated by an insulating dielectric (ceramic layer). The intact seeds selected for the test are placed in a single layer in a homogeneous zone on a glass plate placed under the electrode. The distance of the seed surface from the top electrode was $5 \mathrm{~mm}$. The discharge voltage, current, and power density were $7.0 \mathrm{kV}, 0.2 \mathrm{~A}$, and $3.1 \mathrm{~W} / \mathrm{cm} 2$, respectively. The treatment times were 1 and $2 \mathrm{~min}$ at a distance of $5 \mathrm{~mm}$ between the seed surface and the electrode plate. Seeds were treated at atmospheric pressure, room temperature and 45$55 \%$ air humidity.

The original equipment designed in Vilnius Gediminas Technical university was used for seed treatment with EMF. Seeds were placed for $2 \mathrm{~min}$. in $2.5 \mathrm{~cm}$ above the center of the working induction coil (inner diameter $2.5 \mathrm{~cm}$. outer diameter $3 \mathrm{~cm}$ ). Parameters of the applied EMF treatment were - $100 \mathrm{kHz}, 10 \mathrm{mT}$ (other conditions - room temperature, atmospheric pressure).

For each experimental group 80 seeds were treated. For the control, 80 unaffected seeds of each genotype were used. The total number of seeds used for this study was 2240 ( 7 genotypes x 4 groups x 80 seeds). Control seeds and seeds exposed to CP and EMF treatments 4 days after treatment were sown in cassetes filled with a peat substrate. One month after sowing, maximal seed germination percentage was evaluated and 40 seedlings of each group were left for further growth.

\section{Samples collection}

Samples of the Picea abies seedling needles were collected in three biological replicates from control and affected groups in 2018 and 2019 vegetation seasons (Samples number: 4 Picea abies half-sib families x 3 different effects (CP1, $\mathrm{CP} 2, \mathrm{EMF} 2$ ) and 1 control $\mathrm{x} 3$ biological replicates $=48$ samples and 3 Picea abies half-sib families $\mathrm{x} 2$ different effects $(\mathrm{CP} 1, \mathrm{CP} 2)$ and 1 control $\mathrm{x} 3$ biological replicates $=27$ samples. Two vegetation seasons. Total 150 samples $)$. Biochemical analysis of total phenolic compounds and photosynthesis pigments chlorophyll a and $b$ was carried out to evaluate metabolic changes.

\section{Quantification of Phenolic Compounds}

The $500 \mathrm{mg}$ of fresh needles samples were stored at $-20{ }^{\circ} \mathrm{C}$ until bioactive substances were analyzed. Before analysis, the samples were homogenized by A 11 basic Analytical mill (Laboratory Equipment, Staufen, Germany). The homogenized material was shaken with $10 \mathrm{~mL}$ of $75 \%$ methanol for $24 \mathrm{~h}$ at room temperature using a Kuhner Shaker X electronic shaker (Adolf Kühner AG, Birsfelden, Switzerland). The extracts were filtered through Whatman no. 1 filter paper.

Total phenolic content (TPC) of extracts was assessed by using the Folin-Ciocalteu (FC) reagent method (Singleton et al., 1999). Then, $0.1 \mathrm{~mL}$ of extract was mixed with $0.1 \mathrm{~mL}$ of $2 \mathrm{~N}$ FC reagent and $2.5 \mathrm{~mL}$ of distilled water. After $6 \mathrm{~min}, 0.5 \mathrm{~mL}$ of $20 \% \mathrm{Na}_{2} \mathrm{CO}_{3}$ was added. The extracts were mixed and allowed to stand for 30 min before measuring. The absorbance was measured after $30 \mathrm{~min}$ at $760 \mathrm{~nm}$ using the T80 UV-VIS spectrophotometer (PG Instruments, Leicestershire, UK). The total phenolic content was expressed as chlorogenic acid equivalents in $\mathrm{mg} / 100 \mathrm{~g}$ of fresh material (CAE $\mathrm{mg} / \mathrm{ml})$.

Laboratory analyses were performed at the Institute of Forestry, Lithuanian Research Centre for Agriculture and Forestry (LAMMC).

Statistic analysis 
Data analysis was performed using SAS software (version 9.4). The residual error distributions of the analyzed traits were checked using the UNIVARIATE procedure. No significant deviations from the normal distribution were obtained. Statistical significant differences between the effects was determined by the TTEST procedure, and the overall significance of the effects on the attributes by the GLM procedure, TEST3 (* $\mathrm{p}<0.05 ; * * \mathrm{p}<0.01 ; * * * \mathrm{p}<0.001)$. The MIXED procedure (REML method) was used to calculate the components of the variation using two statistical models. One without genotype and environment interaction (1), the other with interaction (2):

$$
y_{\mathrm{ilm}}=\mu+p_{i}+f_{l}+\varepsilon_{\mathrm{ilm}}
$$

there $y_{\mathrm{ilm}}$ - the observed value for the member of family 1 in treatment i, $\mu$ - the grand mean of the whole test, $p_{i}$ - random effect of the treatment $\mathrm{i}, f_{l}$ - random effect of family $1, \varepsilon_{\mathrm{ilm}}$ - residual error.

Statistical model with interaction between genotype and environment:

$$
y_{\mathrm{ilm}}=\mu+p_{i}+f_{l}+p f_{i l}+\varepsilon_{\mathrm{ilm}}
$$

there $y_{\mathrm{ilm}}$ - the observed value for the member of family 1 in treatment i, $\mu$ - grand meanof the whole test, $p_{i}$ - fixed effect of the treatment $i, f_{l}$ - family random effect of family $1, p f_{i l}$ - random effect of the interaction between the treatment $i$ and family 1 , $\varepsilon_{\mathrm{ilm}}$ - residual error.

\section{RESULTS}

The amount of TPC in Norway spruce needles was determined during two vegetation seasons (in the end of first vegetation and in the beginning of second vegetation season) in order to compare the chemical composition of different Norway spruce half-sib families and their response to seed treatment with physical stressors (CP1, CP2, EMF2). Our results showed that TPC in the half-sib families significantly differed in both affected and control groups. The statistically significant and higher differences of TPC was determined during first year vegetation, comparing to control group (Figure 1 and 2).

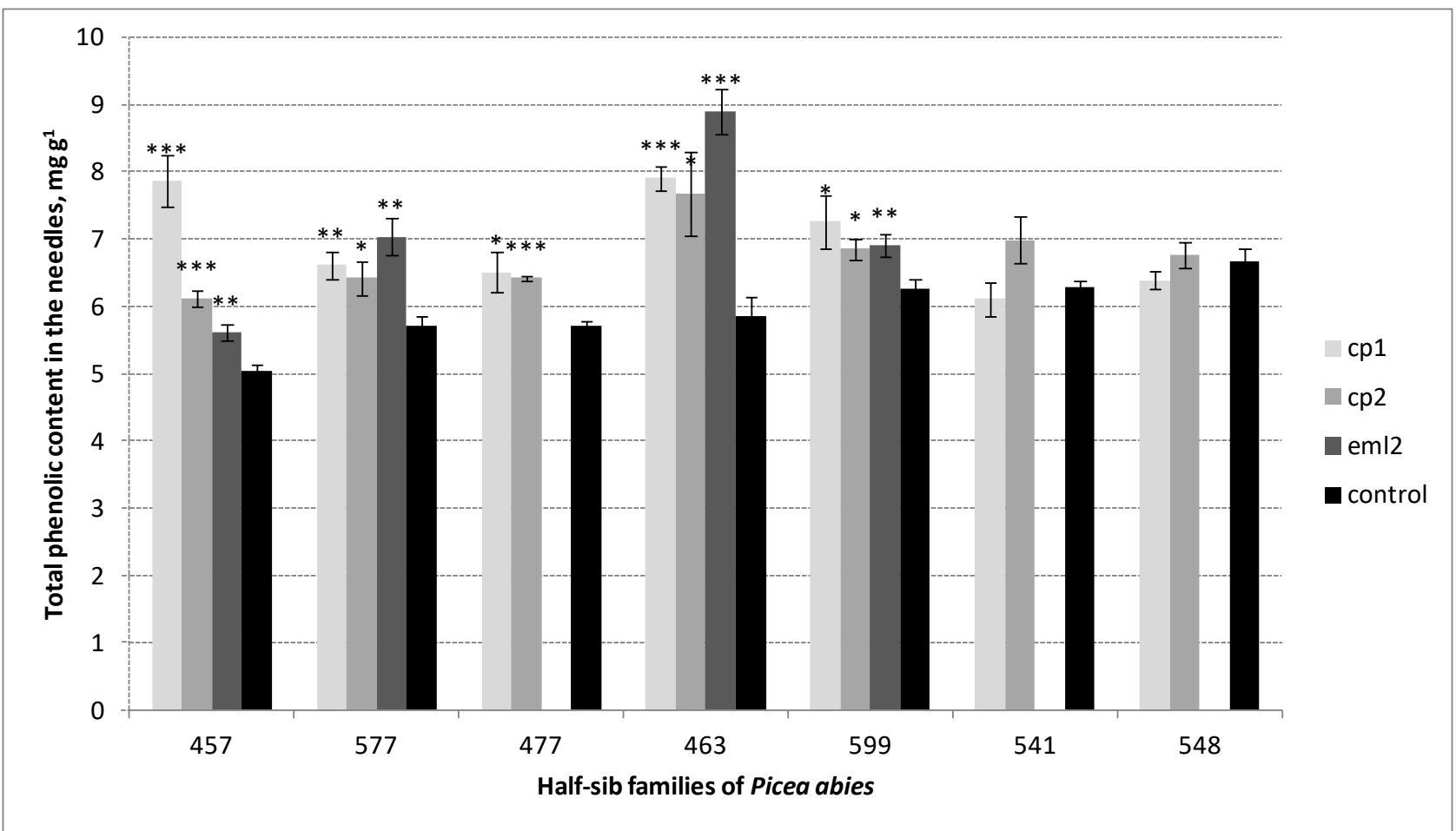

The results are presented as average \pm SE $(n=3)$. The asterisks above the columns indicate the statistical significance of the difference between the treatment group and the control in separate family.

Figure 1. Amount of total phenolic compounds in control and affected half-sib families of Norway spruce during first year of vegetation.

TPC changed depending on the different group of physical stressor applied for the seed treatment during first year vegetation (Figure 1). The physical stressors increased TPC in the needles, comparing to control, in almost all Norway spruce half-sib families, but the most responsive were 457 and 463 families The strongest significant positive effect on TPC synthesis was observed of EMF2 in 463 and 577 half-sib families (by $8,8 \mathrm{mg} \mathrm{g}^{-1}$ and $7 \mathrm{mg} \mathrm{g}^{-1}$, respectively), CP1 in 457 half-sib family (by $7,7 \mathrm{mg} \mathrm{g}^{-1}$, respectively) and CP2 in 541 half-sib family (by 7,9 $\mathrm{mg} \mathrm{g}^{-1}$, respectively), in comparison to control. 
TPC during second year vegetation increased in control group of all Norway spruce half-sib families, comparing to first year vegetation. Meanwhile in different groups of treatment it variated according to effect (Figure 2).

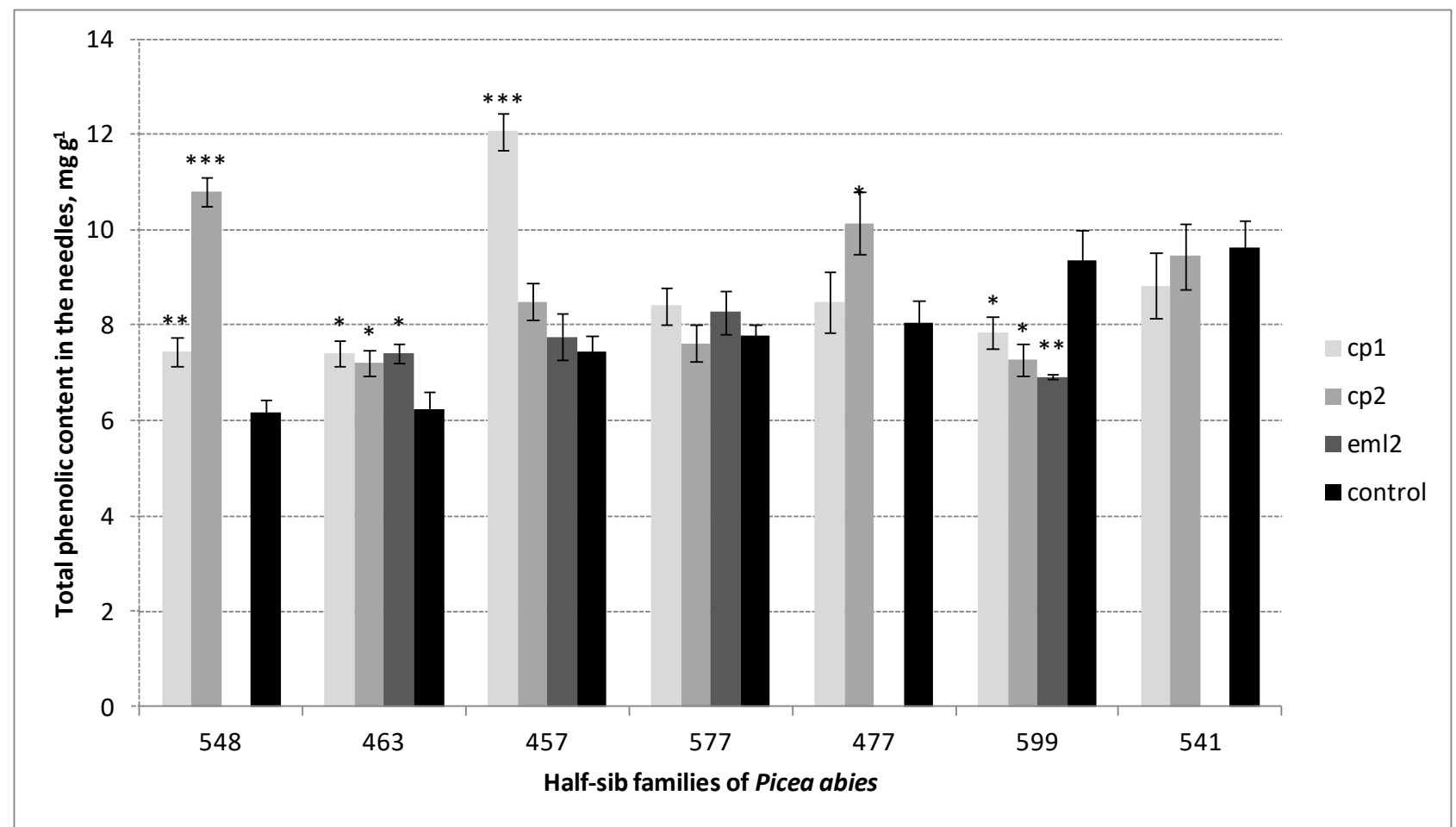

The results are presented as average \pm SEM $(n=3)$. The asterisks above the columns indicate the statistical significance of the difference between the treatment group and the control in separate family.

Figure 2. Amount of total phenolic compounds in affected half-sib families of Norway spruce during second year of vegetation.

The strongest significant positive effect on TPC synthesis of second year seedlings of Norway spruce was observed of CP1 in 457 half-sib family and CP2 in 548 and 477 half-sib families, comparing to control. Statistical analysis of our research showed that half-sib families of Norway spruce was significantly different according to the concentration of total phenolic compounds. The variance component of family for TPC varied from $14 \pm 10 \%$ till $17 \pm 11 \%$, and significant. The interaction of genotype and environment on TPC was as high as $49 \pm 20 \%$.

The pairwise comparison of physical treatments in Norway spruce half-sib families between and with control indicate a significant change in the TPC after physical effects compared to the control group, whereas there was no significant difference between physical effects.

\section{DISCUSSION AND CONCLUSIONS}

The obtained results showed that the amount of TPC in different half-sib families of Norway spruce seedlings was different in the control seedlings. Our study has revealed that seed treatments with CP and EMF induce changes of TPC amount in the seedling needles and the extent of these changes is specific for each half-sib family. For example, in the first vegetation season, TPC production in half-sibfamily 457 was strongly stimulated by CP1, while EMF2 treatment was the most effective for half-sib family 463. Our results confirm findings reported by Mildažienė et al. (2018), that amount of phenolic compounds in E. purpurea leaves was considerably higher in comparison to the control in response to short time ( 2 and $15 \mathrm{~min}$ ) pre-sowing seed treatment with CP and EMF. Sera et al. (2010) reported that seed treatment with CP increased unidentified phenolic compounds up to $65 \%$ in shoots of wheat. The second important result of our study is that changes induced in TPC amounts by seed treatments in different half-sib families of Norway spruce was significantly different, indicating the importance of genotype for the rates of TPC synthesis in general. According to the previous research (Ganthaler et al., 2017; Marčiulynas et al., 2019) high foliar concentrations of secondary phenolic metabolites are associated with pathogen resistance or defense responses. Our findings show that pre-sowing seed treatments with physical stressors potentially may have important practical application for increasing quality forest planting material and increasing disease resistance of Norway spruce. Further studies may be directed towards the selection of Norway spruce half-sib families with low susceptibility to pathogens for breeding programs and forest management strategies. Combination of the pre-sowing seed treatment with physical agents with selection of the most responsive half-sib families characterized by natural high TPC concentration in tissues may lead to the effective solutions for increasing resistance forest trees to pathogens.

\section{REFERENCES}


1. Bourke P., Ziuzina D., Boehm D., Cullen P. J., Keener K. 2018. The Potential of Cold Plasma for Safe and Sustainable Food Production. Trends in Biotechnology, Vol. 36, 6, pp. 615-626. https://doi.org/10.1016/j.tibtech.2017.11.001

2. Filatova I. I., Azharonok V. V., Goncharik S. V., Lyushkevich V. A., Zhukovsky A. G., Gadzhieva G. I. 2014. Effect of rf Plasma Treatment on the Germination and Phytosanitary State of Seed. Journal of Applied. Spectroscopy, Vol. 81, pp. 250-256. https://doi.org/10.1007/s10812-014-9918-5

3. Ganthaler A., Stoggl W., Mayr S., Kranner I., Schuler S., Wischnitzki E., Sehr E. M., Fluch S., Trujillo-Moya C. 2017. Association genetics of phenolic needle compounds in Norway spruce with variable susceptibility to needle bladder rust. Plant Molecular Biology, Vol. 94, pp. 229-251. https://doi.org/10.1007/s11103-017-0589-5

4. Jiang J., Lu Y., Li J., Li L., He X., Shao H., Dong S. 2014. Effect of seed treatment by cold plasma on the resistance of tomato to Ralstonia solanacearum (Bacterial Wilt). PLoS ONE 9, Vol. 5. pp. e97753. https://doi.org/10.1371/journal.pone.0097753

5. Marčiulynas A., Sirgedaitė-Šěžienė V., Žemaitis P., Baliuckas V. 2019. The Resistance of Scots Pine (Pinus sylvestris L.) Half-sib Families to Heterobasidion annosum. Forests, Vol. 10, 3, pp. 287. https://doi.org/10.3390/f10030287

6. Mildažienė V., Paužaitė G., Malakauskienė A., Žūkienė R., Naučienė Z., Filatova I., Azharonok V., Lyushkevich V. 2016. Response of Perennial Woody Plants to Seed Treatment by Electromagnetic Field and Low-Temperature Plasma. Bioelectromagnetics, Vol. 37, pp. 536-548. https://doi.org/10.1002/bem.22003

7. Mildažienė V., Paužaitė G., Naučienė Z., Malakauskienė A., Žūkienė R., Januškaitienè I., Jakštas V., Ivanauskas L., Filatova I., Lyushkevich V. 2017. Pre-sowing seed treatment with cold plasma and electromagnetic field increases secondary metabolite content in purple coneflower (Echinacea purpurea) leaves. Plasma Process and Polymers, Vol. 15, pp. 1-11. https://doi.org/10.1002/ppap.201700059

8. Ohta T. 2016. Plasma in Agriculture. Cold Plasma in Food and Agriculture, 1st. ed., Academic Press, Cambridge, Massachusetts. https://doi.org/10.1016/B978-0-12-801365-6.00008-1

9. Oliva J., Bendz-Hellgren M., Stenlid J. 2011. Spread of Heterobasidion annosum s.s. and Heterobasidion parviporum in Picea abies 15 years after stump inoculation. FEMS Microbiology Ecology, Vol. 75, 3, pp. 414-429. https://doi.org/10.1111/j.1574-6941.2010.01020.x

10. Panngom K., Lee S. H., Park D. H., Sim G. B., Kim Y. H., Uhm H. S., Park G., Choi E. H. 2014. H. Non-thermal plasma treatment diminishes fungal viability and up-regulates resistance genes in a plant host. PLoS ONE, Vol.9, 6, pp. e99300. https://doi.org/10.1371/journal.pone.0099300

11. Paužaitė G., Malakauskienė A., Naučienė Z., Žūkienė R., Filatova I., Lyushkevich V., Azarko I., Mildažienė V. 2017. Changes in Norway spruce germination and growth induced by prie-sowing seed treatment with cold plasma and electromagnetic field: Short-term versus long-term effects. Plasma Processes and Polymers, Vol. 15, 2, pp. 1-11. https://doi.org/10.1002/ppap.201700068

12. Pietrusziewski S., Martinez E. 2015. Magnetic field as a method of improving the quality of sowing material: A review. International Agrophysics, Vol. 29, 29, pp. 377-380. https://doi.org/10.1515/intag-2015-0044

13. Será B, Špatenka B, Šerý P, Vrchotová M, Hrušková N. 2010. Influence of plasma treatment on wheat and oat germination and early growth. IEEE Transactions on Plasma Science, Vool. 38, 10, pp. 2963-2968. https://doi.org/10.1109/TPS.2010.2060728

14. Šera B., Šery M. 2018. Non-thermal plasma treatment as a new biotechnology in relation to seeds, dry fruits, and grains. Plasma Science and Technology, Vol. 20, 4, pp. 1-8. https://doi.org/10.1088/2058-6272/aaacc6

15. Singleton V. L.; Orthofer R., Lamuela-Raventos R. M. 1999. Analysis of total phenols and other oxidation substrates and antioxidants by means of Folin-Ciocalteu reagent. Methods in Enzymology, Vol. 299, pp. 152-178, https://doi.org/10.1016/S0076-6879(99)99017-1

16. Thor M., Stenlid J. 2004. Heterobasidion annosum infection of Picea abies following manual or mechanized stump treatment. Scandinavian Journal of Forest Research, Vol. 20, 2, pp. 154-164. https://doi.org/10.1080/02827580510008338 